\title{
PIK3CA mutation is a favorable prognostic factor in esophageal cancer: molecular profile by next-generation sequencing using surgically resected formalin-fixed, paraffin-embedded tissue
}

Tomoya Yokota', Masakuni Serizawa ${ }^{2}$, Ayumu Hosokawa ${ }^{3}$, Kimihide Kusafuka ${ }^{4}$, Keita Mori ${ }^{5}$, Toshiro Sugiyama ${ }^{3}$, Yasuhiro Tsubosa ${ }^{6}$ and Yasuhiro Koh ${ }^{2,7^{*}}$

\begin{abstract}
Background: Practical and reliable genotyping procedures with a considerable number of samples are required not only for risk-adapted therapeutic strategies, but also for stratifying patients into future clinical trials for moleculartargeting drugs. Recent advances in mutation testing, including next-generation sequencing, have led to the increased use of formalin-fixed paraffin-embedded tissue. We evaluated gene alteration profiles of cancer-related genes in esophageal cancer patients and correlated them with clinicopathological features, such as smoking status and survival outcomes.

Methods: Surgically resected formalin-fixed, paraffin-embedded tissue was collected from 135 consecutive patients with esophageal cancer who underwent esophagectomy. Based on the assessment of DNA quality with a quantitative PCR-based assay, uracil DNA glycosylase pretreatment was performed to ensure quality and accuracy of amplicon-based massively parallel sequencing. Amplicon-based massively parallel sequencing was performed using the Illumina TruSeq ${ }^{\circledast}$ Amplicon Cancer Panel. Gene amplification was detected by quantitative PCR-based assay. Protein expression was determined by automated quantitative fluorescent immunohistochemistry.

Results: Data on genetic alterations were available for 126 patients. The median follow-up time was 1570 days. Amplicon-based massively parallel sequencing identified frequent gene alterations in TP53 (66.7\%), PIK3CA (13.5\%), APC (10.3\%), ERBB4 (7.9\%), and FBXW7 (7.9\%). There was no association between clinicopathological features or prognosis with smoking status. Multivariate analyses revealed that the PIK3CA mutation and clinical T stage were independent favorable prognostic factors (hazard ratio 0.34, 95\% confidence interval: 0.12-0.96, $p=0.042$ ). PIK3CA mutations were significantly associated with APC alterations $(p=0.0007)$ and BRAF mutations $(p=0.0090)$.
\end{abstract}

Conclusions: Our study provided profiles of cancer-related genes in Japanese patients with esophageal cancer by next-generation sequencing using surgically resected formalin-fixed, paraffin-embedded tissue, and identified the PIK3CA mutation as a favorable prognosis biomarker.

Keywords: Esophageal cancer, Formalin-fixed paraffin-embedded tissue, Next-generation sequencing, PIK3CA mutation, Prognostic factors

\footnotetext{
* Correspondence: ykoh@wakayama-med.ac.jp

${ }^{2}$ Drug Discovery and Development Division, Shizuoka Cancer Center

Research Institute, 1007 Shimonagakubo Nagaizumi-cho Sunto-gun, Shizuoka

411-8777, Japan

${ }^{7}$ Third Department of Internal Medicine, Wakayama Medical University, 811-1,

Kimiidera, Wakayama-city, Wakayama 641-0012, Japan

Full list of author information is available at the end of the article
}

(c) The Author(s). 2018 Open Access This article is distributed under the terms of the Creative Commons Attribution 4.0 International License (http://creativecommons.org/licenses/by/4.0/), which permits unrestricted use, distribution, and reproduction in any medium, provided you give appropriate credit to the original author(s) and the source, provide a link to the Creative Commons license, and indicate if changes were made. The Creative Commons Public Domain Dedication waiver (http://creativecommons.org/publicdomain/zero/1.0/) applies to the data made available in this article, unless otherwise stated. 


\section{Background}

Esophageal cancer is one of the most aggressive types of cancer. In contrast to the predominance of adenocarcinoma in western countries, esophageal squamous cell carcinoma (ESCC) is mostly prevalent in eastern Asia, including Japan and China. Epidemiologic studies have established that cigarette smoking and alcohol consumption are strong risk factors for developing ESCC [1]. However, only small number of studies have investigated the prognostic effect of smoking and the association between the molecular characteristics and smoking status in esophageal cancer.

Despite the development of multimodality therapies, including surgical treatment with two- to three-field lymph node dissection [2], adjuvant radiotherapy, chemotherapy [3], and chemoradiotherapy [4], long-term outcome is still unfavorable, even in patients who undergo complete resection of their carcinomas [5].

To improve treatment outcome in patients with esophageal cancer, novel strategies have been developed, especially those that are molecularly targeted. Information on molecular characteristics may have novel therapeutic potential against esophageal cancer. Furthermore, their prognostic or predictive value is extremely useful not only for risk-adapted therapeutic strategies, but also for stratifying patients into future clinical trials for molecular-targeting drugs. For clinical use, practical and reliable genotyping procedures with a considerable number of samples are required. Advances in mutation testing for molecular-targeting drugs, including next-generation sequencing (NGS), have led to the increased use of formalin-fixed paraffin-embedded (FFPE) tissue. Although molecular profiling obtained from a validated comprehensive genomic assay is necessary, there is concern regarding sequencing quality or accuracy when using the DNA extracted from FFPE. We previously demonstrated that the combination strategy of quantitative PCR (qPCR)based DNA quality assessment and uracil DNA glycosylase (UDG) pretreatment improved the accuracy of amplicon-based massively parallel sequencing (MPS) implemented with damaged DNA from FFPE [6].

The goal of this study was to evaluate the profiles of genetic alterations in esophageal cancer and to assess the effect of molecular characteristics on clinical outcome. To this end, we extensively analyzed gene expression and mutations obtained by automated quantitative fluorescent immunohistochemistry (AQUA) and MPS using archived FFPE samples from 135 esophageal cancer patients who underwent surgical resection, and correlated these results with the clinicopathological features, such as smoking status and survival outcomes.

\section{Methods}

\section{Patients and tissues}

Surgically resected FFPE tissue was collected from 135 consecutive patients with esophageal cancer who underwent esophagectomy at the Shizuoka Cancer Center and University of Toyama between October 2002 and November 2011. FFPE specimens were macrodissected to enrich the tumor content for DNA extraction and construction of a tissue microarray. Hematoxylin and eosin-stained slides were retrospectively collected, and presence of tumor cells was verified by experienced gastrointestinal pathologists. However, nine samples were not available for gene analysis because of insufficient tissue status or insufficient coverage for sequencing [6]. Thus, subsequent gene analysis was performed for 126 patients. This study was approved by both institutional review boards (approval number: Shizuoka Cancer Center, T23-3; Toyama University, 22-96).

\section{Genomic DNA extraction}

Tumor samples with a diameter of $2 \mathrm{~mm}$ were punched out from the paraffin block and deparaffinized by $4 \mathrm{~h}$ incubations with xylene at room temperature. A QIAamp DNA FFPE Tissue Kit (QIAGEN, Hilden, Germany) was used to extract genomic DNA from FFPE tumors according to the manufacturer's instructions. DNA concentration was determined using a double-stranded DNA (dsDNA) quantification kit (Quant-iT ${ }^{\mathrm{TM}}$ PicoGreen dsDNA Assay Kit, Life technologies, Carlsbad, CA), and data for each sample were previously described [6]. dsDNA was detectable in 134 of 135 samples.

\section{Assessment of DNA fragmentation with a qPCR-based assay and uracil DNA glycosylase (UDG) pretreatment} A qPCR-based assessment of DNA fragmentation in 134 FFPE DNA samples was performed using the StepOnePlus $^{\text {TM }}$ Real-Time PCR System (Life Technologies) using 4 ng genomic DNA, SYBR ${ }^{\oplus}$ Premix Ex Taq $^{\text {TM }}$ II (Tli RNaseH Plus) (TAKARA BIO, Shiga, Japan), and quality check (QC) primer reagent from the Illumina FFPE QC Kit according to the manufacturer's instructions. Cycle threshold (Ct) in amplicon-based MPS with the TruSeq Amplicon Cancer Panel (TSACP) reflects the sequencing quality in the TSACP assay. Average $\triangle \mathrm{Ct}$ values were calculated by subtracting the $\mathrm{Ct}$ value of the control sample from that of each sample in the three experiments. Average $\Delta \mathrm{Ct}$ values for each tumor sample were described in our previous study [6]. To ensure quality or accuracy of amplicon-based MPS, UDG pretreatment was performed using the method previously described $[6,7]$. The samples with $\Delta \mathrm{Ct}<1.55$ were defined as acceptable sequencing quality. In 88 non-UDG pretreated samples with $\Delta \mathrm{Ct}<1.55,102$ nonsynonymous mutations were detected on the basis of the human genome (hg19) CDS (coding DNA sequence) file. On the other hand, 188 nonsynonymous mutations were 
detected in 38 UDG pretreated samples with $\Delta \mathrm{Ct}$ of 1.55 or greater (Fig. 1).

\section{Amplicon-based MPS with TSACP}

Amplicon-based MPS was performed on MiSeq sequencer (Illumina) using the TruSeq ${ }^{\circledR}$ Amplicon Cancer Panel (Illumina), which was designed to detect somatic mutations in 48 cancer-related genes, according to the manufacturer's instructions. The details of data analysis for amplicon-based MPS with the TSACP assay have been described in our previous study [6]. Eight samples with less than 100x average coverage for non-UDG-pretreated or UDG-pretreated samples or both were omitted; thus, the remaining 126 samples were subjected to subsequent analysis.

\section{Automated quantitative fluorescent immunohistochemistry (AQUA)}

A tissue microarray was constructed and protein expression levels of five representative cancer-related genes in lung and gastrointestinal tumors, including HER2, MET, EGFR, ALK, and HGF, were assessed using automated quantitative fluorescent immunohistochemistry (AQUA). The following primary antibodies were used: antic-erbB-2 Oncoprotein (A0485) (DAKO); anti-MET antibody (SP44); anti-EGFR antibodies (D38B1), Cell Signaling Technology; anti-ALK antibody (5A4), Abcam; and anti-HGF antibody (7-2), Abcam. Mouse IgG2a (Abcam), rabbit polyclonal IgG (Abcam), and normal goat IgG (Santa Cruz Biotechnology) were used as corresponding control antibodies. The AQUA method of quantitative immunofluorescence used to quantitatively measure the biomarkers has been previously described [8]. In brief, monochromatic, high-resolution images were obtained of each histospot after immunofluorescent staining as described herein. Images were captured by the PM-2000 microscope (HistoRx). We distinguished areas of tumor from stromal elements by creating a mask from the cytokeratin signal. A tumor nucleus-specific compartment was created by using the 4',6-diamidino-2-phenylindole (DAPI) signal to identify nuclei, and the cytokeratin signal to define the cytoplasm and membrane. The target signal (AQUA score) was expressed as pixel intensity divided by the target area (tumor nuclei compartment). AQUA scores for triplicate tissue cores were averaged to obtain a mean AQUA score for each tumor. The AQUA scoring was a blind clinical procedure.

\section{Statistical analysis}

The relationships between clinicopathologic variables and smoking status or PIK3CA status were assessed using Fisher's exact test. The Wilcoxon rank sum test was used for analysis of continuous variables. Overall survival (OS) was calculated from the date of surgery until death from any cause, or censored at last follow-up visit. To investigate the prognostic factors, we performed multivariate analysis with the Cox proportional hazard model. The cutoff of protein expression was set to the median AQUA score in multivariate analysis. All $p$-values were two-tailed and $P<0.05$ was considered
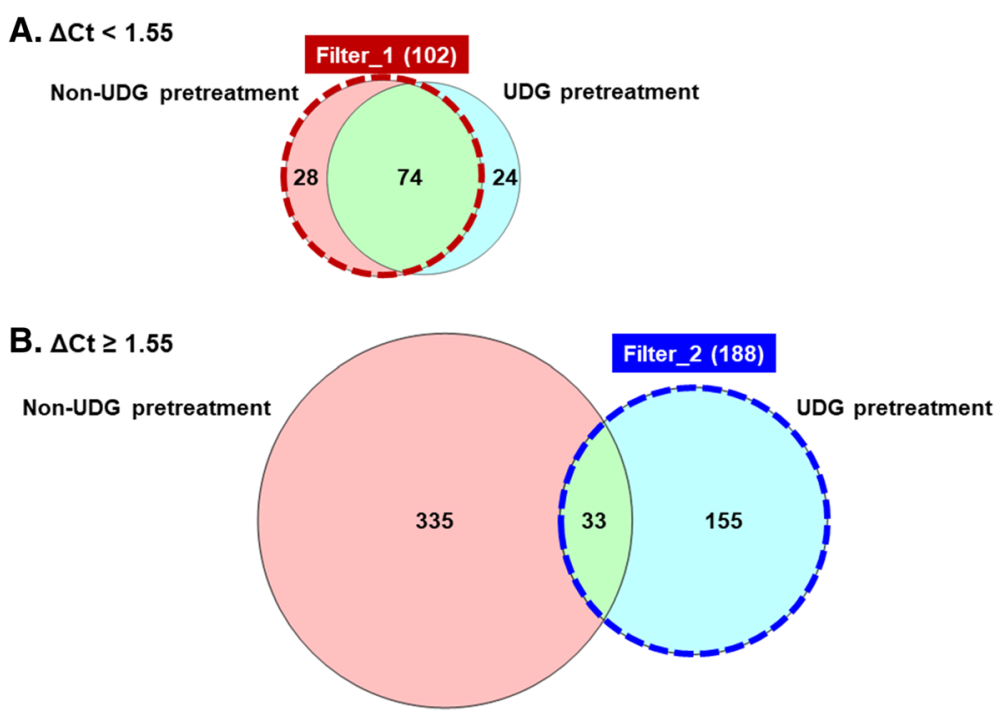

Fig. 1 Venn diagram representing the number of nonsynonymous mutations in the samples with $\Delta \mathrm{Ct}<1.55$ and $\Delta \mathrm{Ct} \geq 1.55$. Each Venn diagram represents the number of nonsynonymous mutations reported in the COSMIC version 71 database with coverage $\geq 250$, frequency $\geq 5 \%$. In the samples with $\Delta \mathrm{Ct}<1.55$, nonsynonymous mutations with non-UDG pretreatment were selected (a), whereas those with UDG pretreatment were selected in the samples with $\Delta \mathrm{Ct} \geq 1.55$ (b) 
statistically significant. We conducted all the analyses using R version 3.2.3 (The R Foundation for Statistical Computing, Vienna, Austria).

\section{Results \\ Association of smoking status with clinicopathological features}

Cumulative smoking dose was evaluated as pack-years (PY), the product of the number of packs consumed per day and years of smoking. In this study, subjects were categorized into four groups based upon PY: smoking status 0: nonsmoker, 1: $0<\mathrm{PY}<20,2$ : $20<\mathrm{PY}<40$, 3: 40 $<$ PY. We then correlated the smoking habit with clinicopathological features of esophageal cancer, including age, gender, primary tumor location, histological findings, TNM stage (UICC 6th), and adjuvant therapy. Females were more frequent in the smoking status 0 group than in other groups. Furthermore, 7.1\% (1 out of 14) of the primary tumors with the smoking status 0 group were located on the cervical esophagus whereas the frequencies of cervical esophageal cancer were $0 \%, 3.3 \%$ (1 out of 30 ), and $0 \%$, for the smoking status 1,2 , and 3 group, respectively. However, there was no association between smoking status and age, histology, TNM stage, or adjuvant therapy (Table 1 ).

\section{Mutational analysis by TSACP}

Mutation analysis was not successful in eight cases because of poor sample condition. Thus, data on genetic alterations were available for 126 patients. Somatic mutational analysis by TSACP identified 290 gene alterations, including single nucleotide variants, deletions, and insertions. The most frequently altered gene was TP53 (mutated in $66.7 \%$ of our cohort), followed by PIK3CA (13.5\%), APC (10.3\%), ERBB4 (7.9\%), FBXW7 (7.9\%), BRAF (7.1\%), RB1 (7.1\%), FLT3 (5.6\%), RET (4.8\%), CDH1 (4.8\%), SMAD4 (4.8\%), VHL (4.0\%), CTNNB1 (4.0\%), KRAS (4.0\%), SMARCB1 (4.0\%), STK11 (4.0\%), and PTEN (3.2\%) (Fig. 2). Most of these genes exhibited missense mutations, followed by nonsense mutations and frameshift mutations, suggesting their tumor suppressor roles. Of all gene alterations in PIK3CA $(n=17)$, gene amplification was detected in three patients $(2.4 \%)$, and PIK3CA mutations occurred in 14 patients $(11.1 \%)$. Of all PIK3CA alterations, $58.8 \%$ were identified in three known hotspots, E542K/E542V (17.6\%) and E545K (23.5\%) in exon 9, and H1047R/ H1047L (23.5\%) in exon 20. Both E542V missense mutations and the frameshift deletion in $\mathrm{H} 554$ were detected in one case. There were 17 APC mutations in 13 patients $(10.3 \%)$, including the nonsense mutation alone $(n$ $=8)$, missense mutation alone $(n=1)$, both frameshift deletion and missense mutation $(n=1)$, and both frameshift deletion and nonsense mutation $(n=1)$ (Fig. 2b). Gene alterations in RB and SMARCB1 were all nonsense mutations. All raw data on somatic mutational analysis by TSACP are shown in Additional file 1.

\section{Effects of smoking status on gene expression and mutation profile}

Median AQUA scores were used as the cut-off point for each protein expression. The association of smoking status with AQUA scores of target gene expression was analyzed by Fisher's exact test. The results revealed no associations between AQUA scores for HER2, MET, EGFR, ALK, and HGF, and smoking status for the entire cohort. The association between smoking status and somatic mutations with base substitutions were further investigated. Although no PIK3CA mutation was observed among non-smokers, no significant correlation between smoking status and gene alteration was observed (Table 1, Fig. 2c). Regardless of smoking status, the most frequent mutation was TP53 (72\% in non/light smoker, 98\% in smokers). In non/light smoker (smoking status $0+1, n=36)$, PIK3CA (17\%), ERBB4 (11\%), FLT3 (11\%), RB1 (8\%), and FBXW7 (4\%) were most frequent, whereas in smokers (smoking status $2+3, n=90$ ), they were APC (17\%), FBXW7 (10\%), PIK3CA (10\%), and BRAF (9\%). No significant differences were found in either composition of mutations or the pattern of base substitutions between smokers and non-smokers (Fig. 3a and b).

\section{Prognostic factors in multivariate analyses}

The median follow-up time was 1570 days. Univariate analysis of OS was performed using clinicopathological variables, aforementioned protein expression, and frequently mutated gene status in TSACP. A factor that was significantly statistically associated with poor OS in this analysis was clinical T stage $(p=0.044)$. Male gender and the p53 mutation were marginally statistically associated with poor OS in all patients (hazard ratio (HR) 2.36; $p=0.096$, HR 1.72; $p=0.059$, respectively). However, patients with PIK3CA mutations had better OS (median OS 2902 days, 95\% CI 1264 days-not reached) than patients with wild-type PIK3CA (median OS 1129 days, 95\% CI 938-1622 days; $p=0.077$ (Table 2, Fig. 4). To adjust for significant prognostic factors, a Cox proportional hazard model that included all factors mentioned above was used. Clinical $\mathrm{T}$ stage was confirmed as an independent negative prognostic factor, whereas the PIK3CA mutation was an independent favorable prognostic factor. Multivariate analysis, including variables whose $p$-value was less than 0.1 in univariate analysis also confirmed that clinical $\mathrm{T}$ stage and the PIK3CA mutation were independent prognostic factors. Specifically, the HR for patients with cT3 was 4.30 (95\% CI: 1.04-17.70) compared to patients with cT1 and 2 (p 
Table 1 Patient characteristics according to smoking history $(n=126)$

\begin{tabular}{lllll}
\hline Smoking status & $0(n=14)$ & $1(n=22)$ & $2(n=30)$ & 3 \\
\hline $\begin{array}{l}\text { Median age (range) } \\
\text { Gender }\end{array}$ & $63(44-73)$ & $64(46-75)$ & $63(42-76)$ & $64(4)$ \\
Male & 10 & 20 & 25 & 57 \\
Female & 4 & 2 & 5 & 3 \\
Location & 1 & 0 & 1 & 0 \\
Ce & 4 & 3 & 1 & 6 \\
Ut & 4 & 6 & 18 & 21 \\
Mt & 5 & 13 & 7 & 28 \\
Lt & 0 & 0 & 3 & 5 \\
Ae & & & &
\end{tabular}

Histology

SCC

Others

TNM (UICC6th)

$\mathrm{T} 1$

$\mathrm{T} 2$

T3

T4

NO

N1

MO

M1a

M1b

Adjuvant

NAC

No NAC

HER2

> median
$<$ median

MET

$>$ median

$<$ median

EGFR

$>$ median

$<$ median

ALK

$>$ median

$<$ median

HGF

$>$ median

$<$ median

TP53

Wild type

Mutation

\section{4}

0

\section{1}

2

11

0

4

10

11

2

1

6

8

4

5

9

6

8

6

8

4

10

7

7
21

1

2

2

18

0

5

17

18

2

2

$3(n$
$64(46-6)$
57
3
0
6
21
28
5

$(n=60)$

$\frac{p \text {-value }}{{ }^{* *} 0.3949}$

${ }^{*} 0.04537$

${ }^{*} 0.642$

2

7

${ }^{*} 0.163$

2

54

2

10

*0.1923

50

51

*0.7328

4

5

31

${ }^{*} 0.8629$

11

29

31

*0.357

29

33

*0.5689

27

32

${ }^{*} 0.8578$

28

*0.4895

31

34

*0.2289

26

20

${ }^{*} 0.372$ 
Table 1 Patient characteristics according to smoking history $(n=126)$ (Continued)

\begin{tabular}{|c|c|c|c|c|c|}
\hline Smoking status & $0(n=14)$ & $1(n=22)$ & $2(n=30)$ & $3(n=60)$ & $p$-value \\
\hline \multicolumn{6}{|l|}{ APC } \\
\hline Wild type & 14 & 20 & 26 & 53 & \multirow[t]{2}{*}{ *0.6702 } \\
\hline Mutation & 0 & 2 & 4 & 7 & \\
\hline \multicolumn{6}{|l|}{ PIK3CA } \\
\hline Wild type & 14 & 16 & 28 & 54 & \multirow[t]{2}{*}{${ }^{*} 0.06858$} \\
\hline Mutation & 0 & 6 & 2 & 6 & \\
\hline \multicolumn{6}{|l|}{ FBXW7 } \\
\hline Wild type & 14 & 19 & 27 & 56 & \multirow[t]{2}{*}{${ }^{*} 0.516$} \\
\hline Mutation & 0 & 3 & 3 & 4 & \\
\hline \multicolumn{6}{|l|}{ BRAF } \\
\hline Wild type & 14 & 20 & 28 & 55 & \multirow[t]{2}{*}{${ }^{*} 0.8769$} \\
\hline Mutation & 0 & 2 & 2 & 5 & \\
\hline
\end{tabular}

Cumulative smoking dose: pack-years $(P Y)=$ Packs/day $\times$ years of smoking

Smoking status 0: non-smoker, Smoking status 1: $0<\mathrm{PY}<20$, Smoking status 2: $20<\mathrm{PY}<40$, Smoking status 3: $40<\mathrm{PY}$

Abbreviation: Ce cervical esophageal cancer, Ut upper thoracic esophageal cancer, $M t$ middle thoracic esophageal cancer, $L t$ lower thoracic esophageal cancer, Ae

abdominal esophageal cancer, SCC squamous cell carcinoma, NAC neoadjuvant chemotherapy

* Fisher's exact test, ** Wilcoxon test

$=0.044)$. Furthermore, the HR for patients with the PIK3CA mutation was 0.34 (95\% CI: 0.12-0.96) compared with patients with the wild-type PIK3CA $(p=$ 0.042) (Table 2). However, the prognostic value of PIK3CA amplification was not statistically significant (HR 2.66; 95\% CI $0.64-11.05 ; p=0.177$ ), and this probably occurred because of the limited number of patients with the PIK3CA amplification $(n=3)$.

\section{Associations between PIK3CA mutations and clinicopathological factors}

We then evaluated the clinicopathological and molecular characteristics of PIK3CA mutations in esophageal cancer. APC gene alterations occurred more frequently in the PIK3CA mutation than in the wild-type ( $p=0.0007)$. BRAF mutations also statistically significantly occurred with the PIK3CA mutations $(p=0.0090)$. However, there was no significant relationship between the PIK3CA mutations and other clinicopathological characteristics (Table 3).

\section{Discussion}

In this study, we determined the genetic profiles of 126 Japanese esophageal cancer patients by NGS and AQUA using DNA from FFPE samples. Our cohort was non-biased consecutive cases, which consisted mostly of ESCC, but also of those with non-ESCC histology. Amplicon-based MPS identified mutations in TP53, PIK3CA, APC, ERBB4, and FBXW7 as the most frequent gene alterations. We further examined the prognostic effect of these gene mutations, and found that the PIK3CA mutation, as well as the clinical T stage were independent prognostic factors. Importantly, patients with the PIK3CA mutations had significantly better survival than those with the wild-type PIK3CA. To the best of our knowledge, the present report is the first to investigate the prognostic significance of PIK3CA mutations based on NGS data in esophageal cancer.

One of the goals in this study was to characterize the smoking status in esophageal cancer. However, there was no association between clinicopathological features or prognosis and smoking status. Furthermore, our molecular analysis by NGS suggested there were no significant differences in the mutation spectrum and the pattern of base substitutions between smokers and non-smokers, unlike that of non-small-cell lung cancer patients who underwent surgery [9]. These results are consistent with previous exome sequencing in ESCC from China [10], and support the hypothesis that smoking might contribute to tumorigenesis of esophageal cancer through distinct mechanisms similar to those in other smoking-related cancers.

PIK3CA, which encodes the p110a catalytic subunit of the phosphoinositide 3-kinase (PI3K) [11, 12], is an oncogene in various cancers, and its mutation or amplification and subsequent activation of the PI3K/AKT signaling pathway regulates cell proliferation, growth, survival, apoptosis, and glucose metabolism [13]. The frequency of PIK3CA mutations has been reported to range from 1.5 to $22.9 \%$ in ESCC [10, 14-23], as well as in Barrett's esophagus [24]. In our study, $13.5 \%$ of cases were identified as having a PIK3CA mutation or amplification, all of which presented squamous cell carcinoma histology. Therefore, PIK3CA serves as a potential therapeutic target in ESCC. Hotspot mutations of PIK3CA in 


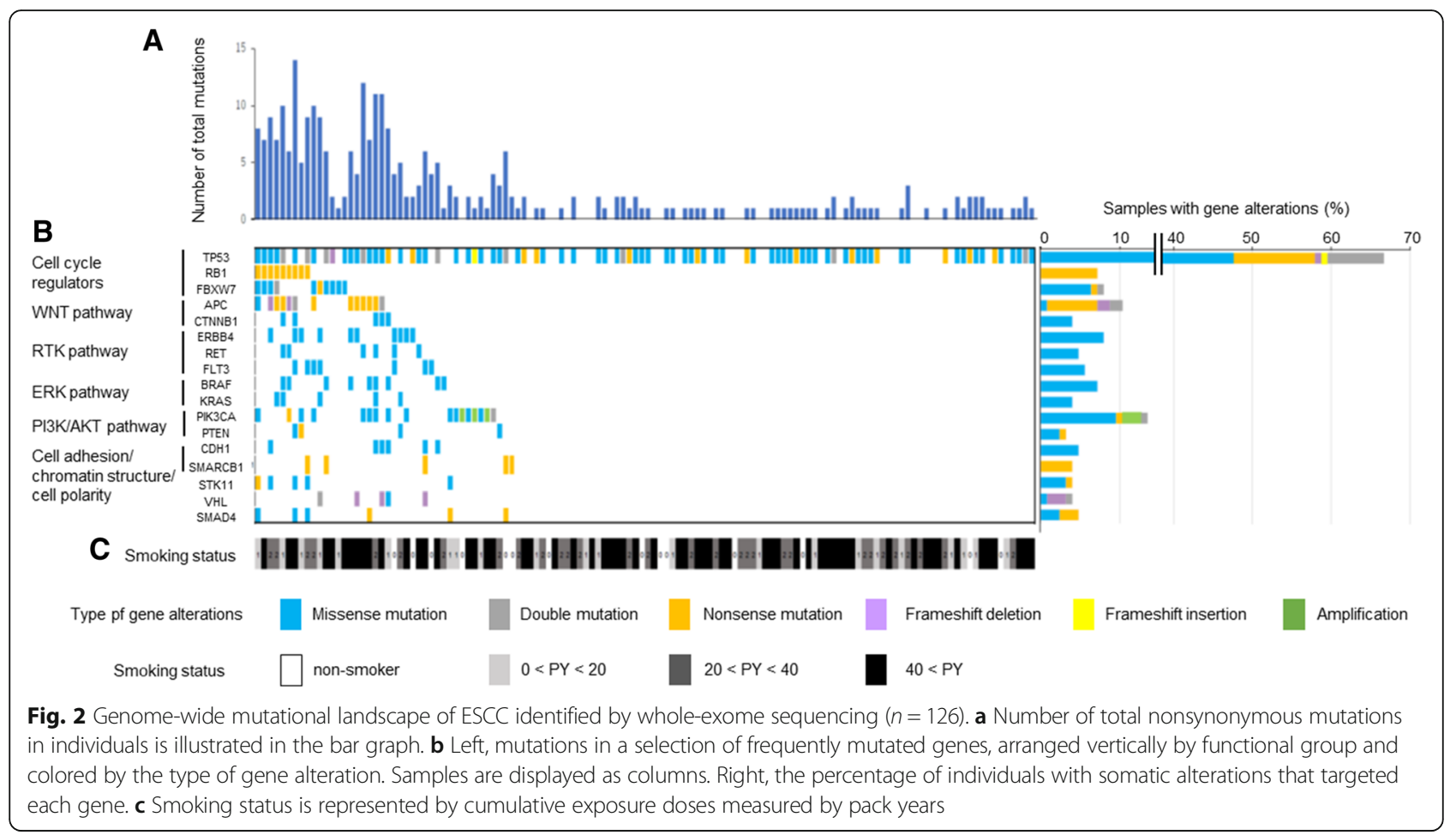

Table 2 Factors associated with overall survival in univariate and multivariate analyses

\begin{tabular}{|c|c|c|c|c|c|c|c|}
\hline \multirow[b]{2}{*}{ Factors } & \multirow[b]{2}{*}{ Category } & \multicolumn{2}{|l|}{ Univariate analysis } & \multicolumn{2}{|c|}{ Multivariate analysis (including all variables) } & \multicolumn{2}{|c|}{ Multivariate analysis } \\
\hline & & $\mathrm{HR}(95 \% \mathrm{Cl})$ & $p$-value & $\mathrm{HR}(95 \% \mathrm{Cl})$ & $p$-value & HR $(95 \% \mathrm{Cl})$ & $p$-value \\
\hline Age & $\geq 65$ (vs. <65) & $1.11(0.68-1.79)$ & 0.68 & $1.25(0.74-2.11)$ & 0.40 & & \\
\hline Male & Male (vs. Female) & $2.36(0.86-6.49)$ & 0.096 & $2.48(0.86-7.20)$ & 0.094 & $2.30(0.83-6.36)$ & 0.11 \\
\hline Smoking status & $2-3$ (vs $0-1$ ) & $1.22(0.71-2.13)$ & 0.47 & $0.74(0.40-1.36)$ & 0.33 & & \\
\hline cT & T3 (vs. T1, T2) & $4.25(1.04-17.41)$ & 0.044 & $5.23(1.19-23.00)$ & 0.029 & $4.30(1.04-17.70)$ & 0.044 \\
\hline $\mathrm{cN}$ & N1 (vs. N0) & $1.52(0.84-2.75)$ & 0.16 & $1.12(0.57-2.19)$ & 0.75 & & \\
\hline NAC & Without (vs. with) & $1.01(0.62-1.65)$ & 0.97 & $0.88(0.52-1.50)$ & 0.65 & & \\
\hline HER2 & >median (vs. <median) & $0.93(0.57-1.50)$ & 0.76 & $0.92(0.54-1.55)$ & 0.75 & & \\
\hline MET & >median (vs. <median) & $0.75(0.46-1.21)$ & 0.24 & $0.74(0.44-1.27)$ & 0.28 & & \\
\hline EGFR & >median (vs. <median) & $0.99(0.61-1.60)$ & 0.97 & $0.95(0.56-1.62)$ & 0.86 & & \\
\hline ALK & >median (vs. <median) & $1.17(0.72-1.89)$ & 0.52 & $1.14(0.68-1.92)$ & 0.61 & & \\
\hline $\mathrm{HGF}$ & >median (vs. <median) & $1.29(0.80-2.09)$ & 0.29 & $1.34(0.77-2.33)$ & 0.29 & & \\
\hline p53 & Mutation (vs. wild type) & $1.72(0.98-3.03)$ & 0.059 & $1.51(0.82-2.81)$ & 0.19 & $1.55(0.88-2.73)$ & 0.13 \\
\hline PIK3CA & Mutation (vs. wild type) & $0.40(0.14-1.10)$ & 0.077 & $0.28(0.09-0.90)$ & 0.033 & $0.34(0.12-0.96)$ & 0.042 \\
\hline APC & Mutation (vs. wild type) & $0.87(0.40-1.90)$ & 0.72 & $0.81(0.23-2.86)$ & 0.74 & & \\
\hline ERBB4 & Mutation (vs. wild type) & $0.63(0.23-1.73)$ & 0.37 & $0.91(0.27-3.10)$ & 0.88 & & \\
\hline FBXW7 & Mutation (vs. wild type) & $0.56(0.20-1.54)$ & 0.26 & $0.43(0.13-1.44)$ & 0.17 & & \\
\hline BRAF & Mutation (vs. wild type) & $0.99(0.40-2.47)$ & 0.99 & $1.83(0.56-6.04)$ & 0.32 & & \\
\hline RB1 & Mutation (vs. wild type) & $1.03(0.41-2.57)$ & 0.95 & $1.79(0.52-6.11)$ & 0.35 & & \\
\hline
\end{tabular}




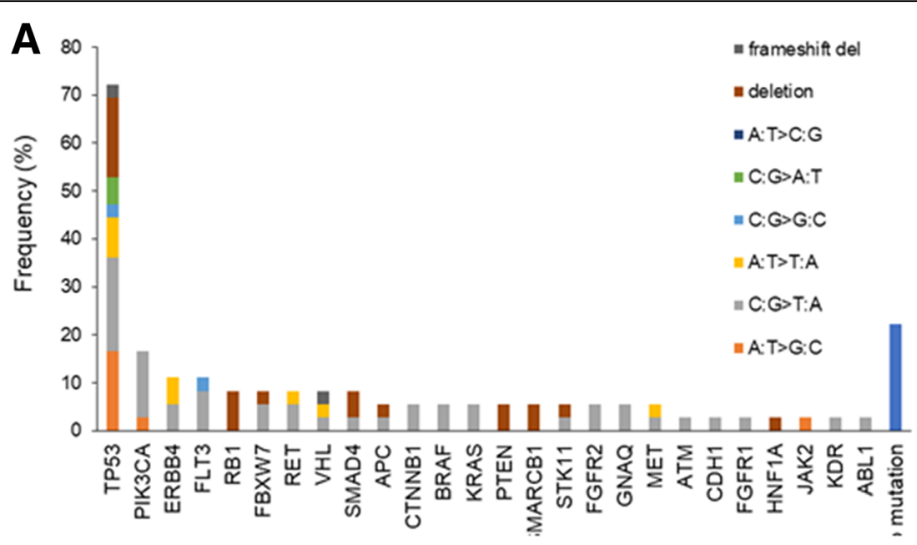

B

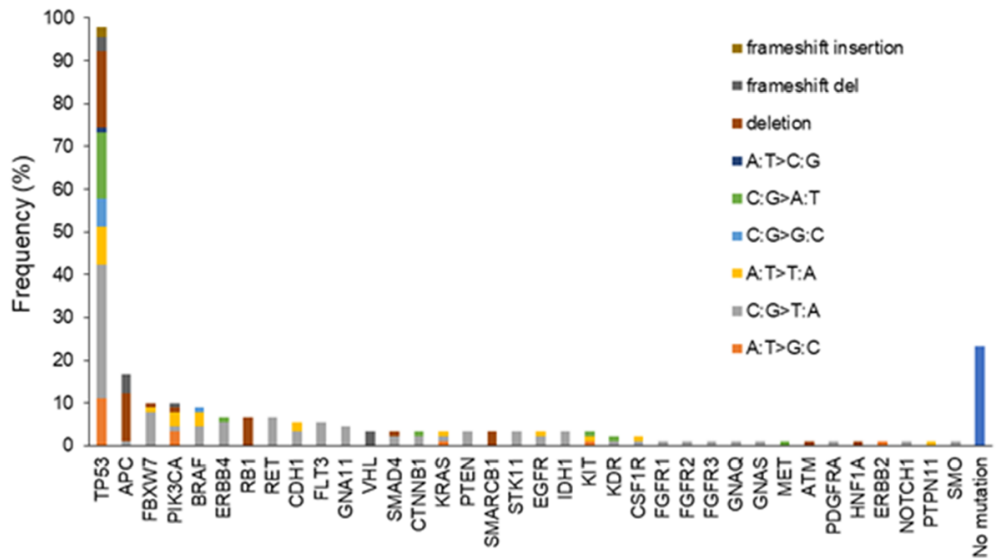

Fig. 3 Frequency of somatic mutations with base substitution in non/light smoker $(n=36)$ and smokers $(n=90)$. Frequencies of somatic mutations are shown for indicated genes in (a) non/light smokers (smoking status $0+1$ ) and (b) smokers (smoking status $2+3$ ). Deletions, insertions, and six types of point mutations are differentially shown by colors

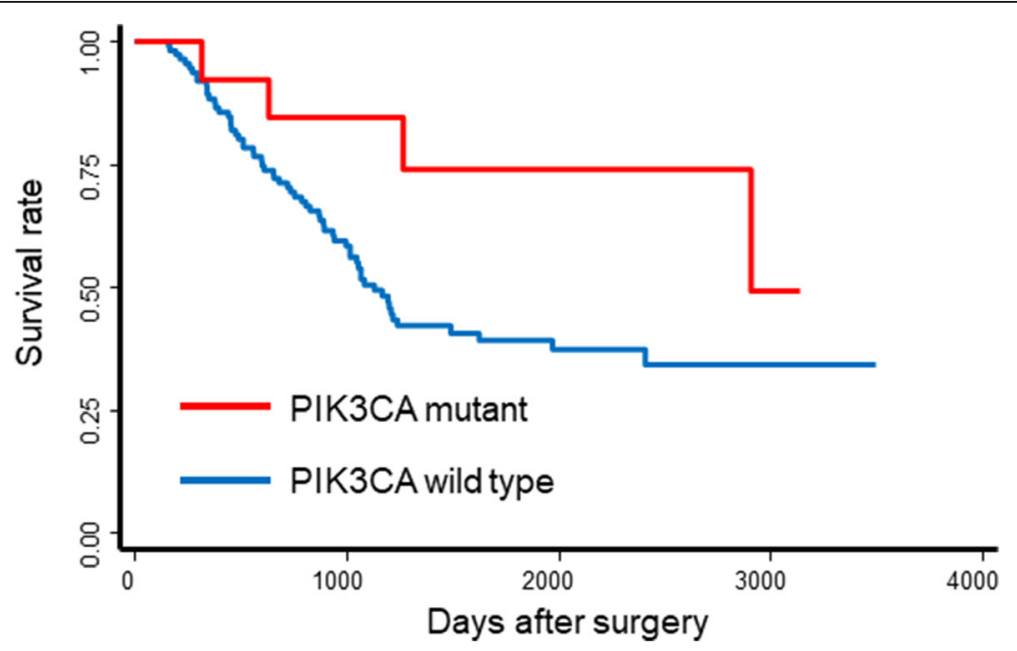

Fig. 4 Kaplan-Meier plot showing overall survival in esophageal cancer patients according to PIK3CA mutational status $(n=126)$ 
Table 3 PIK3CA status and associated clinicopathological factors $(n=126)$

\begin{tabular}{|c|c|c|c|c|c|}
\hline \multirow[t]{2}{*}{ Variable } & \multicolumn{2}{|c|}{ PIK3CA mutant } & \multicolumn{2}{|c|}{ PIK3CA wild type } & \multirow[b]{2}{*}{$p$-value } \\
\hline & $\mathrm{N}$ & $\%$ & $\mathrm{~N}$ & $\%$ & \\
\hline \multicolumn{6}{|l|}{ Age } \\
\hline$<65$ & 7 & 50.0 & 63 & 56.3 & \multirow[t]{2}{*}{0.7776} \\
\hline$\geq 65$ & 7 & 50.0 & 49 & 43.8 & \\
\hline \multicolumn{6}{|l|}{ Gender } \\
\hline Male & 13 & 92.9 & 99 & 88.4 & \multirow[t]{2}{*}{1.0000} \\
\hline Female & 1 & 7.1 & 13 & 11.6 & \\
\hline \multicolumn{6}{|c|}{ Smoking status } \\
\hline 0 & 0 & 0.0 & 14 & 12.5 & \\
\hline 1 & 6 & 42.9 & 16 & 14.3 & \multirow[t]{3}{*}{0.06858} \\
\hline 2 & 2 & 14.3 & 28 & 25.0 & \\
\hline 3 & 6 & 42.9 & 54 & 48.2 & \\
\hline \multicolumn{6}{|l|}{ Location } \\
\hline $\mathrm{Ce}$ & 0 & 0.0 & 2 & 1.8 & \multirow[t]{5}{*}{0.9269} \\
\hline Ut & 1 & 7.1 & 13 & 11.6 & \\
\hline Mt & 6 & 42.9 & 43 & 38.4 & \\
\hline $\mathrm{Lt}$ & 7 & 50.0 & 46 & 41.1 & \\
\hline $\mathrm{Ae}$ & 0 & 0.0 & 8 & 7.1 & \\
\hline \multicolumn{6}{|l|}{ Histology } \\
\hline SCC & 14 & 100.0 & 102 & 91.1 & \multirow[t]{2}{*}{0.6007} \\
\hline Others & 0 & 0.0 & 10 & 8.9 & \\
\hline \multicolumn{6}{|c|}{ TNM (UICC6th) } \\
\hline $\mathrm{T} 1$ & 0 & 0.0 & 5 & 4.5 & \multirow[t]{4}{*}{0.2775} \\
\hline $\mathrm{T} 2$ & 1 & 7.1 & 5 & 4.5 & \\
\hline $\mathrm{T} 3$ & 12 & 85.7 & 101 & 90.2 & \\
\hline $\mathrm{T} 4$ & 1 & 7.1 & 1 & 0.9 & \\
\hline NO & 4 & 28.6 & 26 & 23.2 & \multirow[t]{2}{*}{0.7402} \\
\hline N1 & 10 & 71.4 & 86 & 76.8 & \\
\hline MO & 11 & 78.6 & 93 & 83.0 & \multirow[t]{3}{*}{0.4465} \\
\hline M1a & 2 & 14.3 & 7 & 6.3 & \\
\hline M1b & 1 & 7.1 & 12 & 10.7 & \\
\hline \multicolumn{6}{|l|}{ Adjuvant } \\
\hline NAC & 7 & 50.0 & 58 & 51.8 & \multirow[t]{2}{*}{1.0000} \\
\hline No NAC & 7 & 50.0 & 54 & 48.2 & \\
\hline \multicolumn{6}{|l|}{ HER2 } \\
\hline$>$ median & 9 & 64.3 & 55 & 49.1 & \multirow[t]{2}{*}{0.3969} \\
\hline$<$ median & 5 & 35.7 & 57 & 50.9 & \\
\hline \multicolumn{6}{|l|}{ MET } \\
\hline$>$ median & 6 & 42.9 & 61 & 54.5 & \multirow[t]{2}{*}{0.5715} \\
\hline$<$ median & 8 & 57.1 & 51 & 45.5 & \\
\hline EGFR & & & & & \\
\hline$>$ median & 5 & 35.7 & 57 & 50.9 & 0.3969 \\
\hline$<$ median & 9 & 64.3 & 55 & 49.1 & \\
\hline
\end{tabular}


Table 3 PIK3CA status and associated clinicopathological factors $(n=126)$ (Continued)

\begin{tabular}{|c|c|c|c|c|c|}
\hline \multirow[t]{2}{*}{ Variable } & \multicolumn{2}{|c|}{ PIK3CA mutant } & \multicolumn{2}{|c|}{ PIK3CA wild type } & \multirow[b]{2}{*}{$p$-value } \\
\hline & $\mathrm{N}$ & $\%$ & $\mathrm{~N}$ & $\%$ & \\
\hline \multicolumn{6}{|l|}{ ALK } \\
\hline$>$ median & 7 & 50.0 & 55 & 49.1 & 1.0000 \\
\hline$<$ median & 7 & 50.0 & 57 & 50.9 & \\
\hline \multicolumn{6}{|l|}{ HGF } \\
\hline$>$ median & 6 & 42.9 & 55 & 49.1 & 0.7796 \\
\hline$<$ median & 8 & 57.1 & 57 & 50.9 & \\
\hline \multicolumn{6}{|l|}{ TP53 } \\
\hline Wild type & 4 & 28.6 & 38 & 33.9 & 0.7728 \\
\hline Mutation & 10 & 71.4 & 74 & 66.1 & \\
\hline \multicolumn{6}{|l|}{ APC } \\
\hline Wild type & 8 & 57.1 & 105 & 93.8 & 0.0007 \\
\hline Mutation & 6 & 42.9 & 7 & 6.3 & \\
\hline \multicolumn{6}{|l|}{ ERBB4 } \\
\hline Wild type & 12 & 85.7 & 104 & 92.9 & 0.3070 \\
\hline Mutation & 2 & 14.3 & 8 & 7.1 & \\
\hline \multicolumn{6}{|l|}{ FBXW7 } \\
\hline Wild type & 12 & 85.7 & 104 & 92.9 & 0.3070 \\
\hline Mutation & 2 & 14.3 & 8 & 7.1 & \\
\hline \multicolumn{6}{|l|}{ BRAF } \\
\hline Wild type & 10 & 71.4 & 107 & 95.5 & 0.0090 \\
\hline Mutation & 4 & 28.6 & 5 & 4.5 & \\
\hline \multicolumn{6}{|l|}{ RB1 } \\
\hline Wild type & 11 & 78.6 & 106 & 94.6 & 0.0618 \\
\hline Mutation & 3 & 21.4 & 6 & 5.4 & \\
\hline
\end{tabular}

exon 9 and exon 20 are known to be oncogenic in various tumor types, including esophageal, colorectal, brain, and gastric cancers [25]. PIK3CA mutations were not significantly associated with any clinicopathological characteristics, except for the APC and BRAF genotype as discussed below, which was consistent with the results of other studies in Korea, China, and Japan [17, 19, 26].

The prognostic relevance of PIK3CA mutations has been investigated in various solid tumors, and PIK3CA mutations are generally associated with an unfavorable prognosis in patients with colorectal [27-30] or lung cancer [31]. On the other hand, studies on breast and ovarian cancer demonstrated that the patients with the PIK3CA mutation showed a trend towards a favorable prognosis [32-34]. These reports suggest that PIK3CA mutations might behave differently according to tumor type. Our multivariate analysis revealed that PIK3CA gene mutations were associated with a favorable prognosis among Japanese patients with curatively resected esophageal cancer, mainly ESCC, suggesting that the PIK3CA gene mutational status may be a prognostic biomarker for Japanese esophageal cancer patients. This finding supports other studies in Chinese and Japanese ESCC patients $[16,19,22]$. We further separately analyzed the survival in patients with PIK3CA mutations in coding exon 9 and 20. Median OS in patients with exon 9 mutation was not reached, and that in patients with exon 20 mutation was 2902 days (95\% CI 693 days-not reached). That is, both patients with exon 9 and $20 \mathrm{mu}-$ tation had better OS than patients with wild-type PIK3CA. These findings suggest that both exon 9 and 20 mutation might be favorable prognostic factors. However, due to limited sample size for each type of PIK3CA mutation (6 patients in exon 9, 7 patients in exon 20, and 1 in exon 7), it is hard to differentially conclude the significance of each mutation as a prognostic marker. Taken together, the prognostic effect of the PIK3CA mutation in ESCC has been controversial, despite a number of investigations dating from the 2010s in Asia (Table 4).

The possible reasons for the different results might be different patient cohorts, sample sizes, methods used to assess PIK3CA mutations, or ethnicity. First, the patient 
Table 4 Prognostic significance of PIK3CA alterations in esophageal cancer

\begin{tabular}{|c|c|c|c|c|c|c|c|c|}
\hline Author & $\begin{array}{l}\text { Sample } \\
\text { size }(N)\end{array}$ & Histology & $\begin{array}{l}\text { Type of PIK3CA } \\
\text { alterations }\end{array}$ & $\begin{array}{l}\text { Frequency } \\
(\%)\end{array}$ & $\begin{array}{l}\text { Prognostic } \\
\text { effect }\end{array}$ & HR $(95 \% \mathrm{Cl})$ & Material & Method \\
\hline $\begin{array}{l}\text { Maeng et al. } \\
(2012) \text { [17] }\end{array}$ & 80 & ESCC & $\begin{array}{l}\text { Exon } 9 \text { and } 20 \\
\text { mutations }\end{array}$ & 11.5 & N.S. & NA & $\begin{array}{l}\text { Primary\& } \\
\text { Metastatic sites } \\
\text { FFPE }\end{array}$ & $\begin{array}{l}\text { Mass-spectrometry } \\
\text { based assay }\end{array}$ \\
\hline $\begin{array}{l}\text { Shigaki et al. } \\
\text { (2013) [19] }\end{array}$ & 219 & ESCC & $\begin{array}{l}\text { Exon } 9 \text { and } 20 \\
\text { mutations }\end{array}$ & 21 & Favorable OS & $0.35(0.10-0.90)$ & $\begin{array}{l}\text { Surgically resected } \\
\text { FFPE }\end{array}$ & Pyrosequencing \\
\hline $\begin{array}{l}\text { Hou et al. } \\
\text { (2014) [16] }\end{array}$ & 96 & ESCC & $\begin{array}{l}\text { Exon } 9 \text { and } 20 \\
\text { mutations }\end{array}$ & 12.5 & $\begin{array}{l}\text { Trend towards } \\
\text { favorable OS }\end{array}$ & NA & $\begin{array}{l}\text { Surgically resected } \\
\text { FFPE }\end{array}$ & $\begin{array}{l}\text { Mutant enriched } \\
\text { PCR method }\end{array}$ \\
\hline $\begin{array}{l}\text { Wang et al. } \\
(2014)[21]\end{array}$ & 406 & ESCC & $\begin{array}{l}\text { Exon } 9 \\
\text { mutations }\end{array}$ & 7.4 & N.S. & $1.256(0.748-2.108)$ & $\begin{array}{l}\text { Surgically resected } \\
\text { FFPE }\end{array}$ & Direct sequencing \\
\hline \multirow[t]{2}{*}{$\begin{array}{l}\text { Kim et al. } \\
\text { (2016) [23] }\end{array}$} & 534 & ESCC & Amplification & 10.5 & $\begin{array}{l}\text { Trend towards } \\
\text { unfavorable OS }\end{array}$ & $1.21(0.83-1.77)$ & $\begin{array}{l}\text { Surgically resected } \\
\text { FFPE }\end{array}$ & $\begin{array}{l}\text { Fluorescent in situ } \\
\text { hybridization }\end{array}$ \\
\hline & 388 & & $\begin{array}{l}\text { Exon } 9 \text { and } 20 \\
\text { mutations }\end{array}$ & 1.5 & N.S. & NA & & Direct sequencing \\
\hline $\begin{array}{l}\text { Liu et al. } \\
\text { (2017) [22] }\end{array}$ & 210 & ESCC & $\begin{array}{l}\text { Exon } 9 \\
\text { mutations }\end{array}$ & 22.9 & Favorable OS & NA & $\begin{array}{l}\text { Surgically resected } \\
\text { FFPE }\end{array}$ & Pyrosequencing \\
\hline \multirow[t]{2}{*}{$\begin{array}{l}\text { Current } \\
\text { study }\end{array}$} & 126 & $\begin{array}{l}\text { Mostly } \\
\text { ESCC }\end{array}$ & $\begin{array}{l}\text { Exon } 9 \text { and } 20 \\
\text { mutations }\end{array}$ & 11.1 & Favorable OS & $0.34(0.12-0.96)$ & $\begin{array}{l}\text { Surgically resected } \\
\text { FFPE }\end{array}$ & MPS with TSACP \\
\hline & & & Amplification & 2.4 & N.S. & $2.66(0.64-11.05)$ & & \\
\hline
\end{tabular}

Abbreviations: OS overall survival, HR hazard ratio, CI confidence interval, NA not available, FFPE formalin-fixed paraffin-embedded, N.S. not significant, ESCC esophageal squamous cell carcinoma, MPS massively parallel sequencing, TSACP TruSeq ${ }^{\oplus}$ Amplicon Cancer Panel

cohort in Maeng et al. had metastatic ESCC, which differed from those studies using surgically resected primary sites [17]. Next, we used amplicon-based MPS, which is a NGS technology and increasingly being used for mutational analysis of tumors for both clinical and research applications. NGS facilitates multi-gene mutational profiling with only nanograms of DNA and has better sensitivity than traditional sequencing platforms, such as direct sequencing $[35,36]$. Indeed, the limited sensitivity of direct sequencing may result in an apparent the low frequency of PIK3CA mutations [21, 23]. Although allele-specific mutation testing, including pyrosequencing and mass-spectrometry based assays, was shown to be more sensitive than regular direct sequencing, its potential disadvantage is the ability to assess only limited hotspot regions in given genes [37]. Therefore, different sequencing methodologies may have an effect on the frequency of PIK3CA mutations, leading to different prognostic values. Furthermore, although FFPE samples are the most practically available material when performing mutation testing, one of the pitfalls of using FFPE samples is DNA fragmentation [38] and artificial C: G > T: A single nucleotide variants because of deamination of cytosine to uracil. Therefore, DNA quality assessment is essential in mutation testing, especially in highly sensitive sequencing methods. We previously demonstrated that UDG pretreatment is efficacious for excluding nonspecific single nucleotide variants in amplicon-based MPS that occur if poor-quality DNA from FFPE samples was used. This may be a reason why the frequency of the PIK3CA mutation in our study was not higher than previous allele-specific mutation testing. Although the data on molecular profiling in this study was obtained from a validated comprehensive genomic assay, one of the limitations of this study is that our findings were not validated by other methods. Furthermore, because the sample size for each type of mutation was small, our results should be further validated in some independent cohorts in the future.

It is expected that PIK3CA mutations would imply poor clinical outcome, because the presence of oncogene activation leads to aggressive tumor behavior. However, this was not true. One possible hypothesis to explain the paradoxical result may be a negative feedback mechanism through which the PI3K/AKT pathway is inactivated in PIK3CA mutant tumors. In wild-type PIK3CA tumors, on the contrary, the PI3K/AKT pathway may be activated by several factors, such as EGFR and HER2, independent of PIK3CA mutation. Indeed, the relationship between PIK3CA mutation and p-AKT expression has been different among tumor types [19, 34]. Otherwise, wild-type PIK3CA tumors may require alternative molecular alterations to the PI3K/AKT pathway to acquire more aggressive phenotypes. However, all of them have not been proven yet, and our AQUA system did not include p-AKT expression. Therefore, such compensatory mechanisms need to be further elucidated in the future.

To further characterize the PIK3CA mutation and wild-type, we also investigated the clinicopathological characteristics of esophageal cancer patients with respect to PIK3CA status. PIK3CA mutations were significantly associated with the APC mutation. The type of APC 
gene alteration detected in this study was different from that reported to occur frequently in upper gastrointestinal cancers, such as at codons 1450, 1462-1465, and 1554-1556 [39]. The most frequently noted mutations in our cohort were nonsense mutations $(11 / 17 ; 64.7 \%)$, which resulted in truncated APC proteins. APC frameshift deletions in the codon 1556 hot spot, 1301, and 1384 detected in this study also lead to loss of APC function. The coexistence of APC alterations with PIK3CA mutation may be partially explained by a previous study using a mouse model with PIK3CA mutation, which demonstrated that the PIK3CA mutation alone was insufficient to initiate intestinal tumorigenesis in intestinal cancers. Thus, loss of APC activity may synergistically act with active PI3K, resulting in tumorigenesis [40, 41].

As compared to PIK3CA alterations, the mutations involved in the RAS-RAF pathway were rare. Previous analysis by a mass-spectrometry based assays revealed that only one of 80 patients harbored an oncogenic BRAFV600E mutation [17]. In our series, no BRAFV600E mutation was detected. Instead, there were nine cases with BRAF mutations at codons $598(n=3), 469(n=2)$, and $444(n=2)$. We also found statistically significant coexistence of BRAF mutations and PIK3CA mutations. However, the biological relevance of the coexistence of these mutations remains unclear.

Furthermore, Zhang et al. successfully established and characterized patient-derived esophageal squamous cell carcinoma xenograft (PDECX) mouse models, and found that PDECX models with PIK3CA mutation had no significant response to cytotoxic agents. This result suggests that PIK3CA mutation is also involved in sensitivity to chemotherapy, and may provide an information for the treatment of ESCC patients in the future [42].

Recent treatment strategies for advanced esophageal cancer have shifted to neoadjuvant treatment, such as chemotherapy and chemoradiotherapy [3, 4]. The limitation of this study is that some of the surgically resected specimens may have been modified by preoperative therapy. Therefore, we also separately analyzed the survival for a cohort with preoperative treatment $(n=65)$ from that without preoperative therapy $(n=61)$. However, PIK3CA mutational status was not significantly associated with survival, probably because of the small sample size for PIK3CA mutations in each cohort. Furthermore, protein expression measured by AQUA may be modified by preoperative treatment. That could be a main reason why any gene expression was not significantly associated with prognosis in our study. Indeed, for instance, the prognostic effect of EGFR protein expression was proved by immunohistochemistry using surgically resected tumor tissue in patients with ESCC who underwent surgery alone or surgery and postoperative radiotherapy [43].

\section{Conclusions}

Our study provides comprehensive genomic profiling of resected esophageal cancer by NGS using surgically resected FFPE tissue and identified PIK3CA mutations as a favorable prognosis biomarker. Our study supports previous findings obtained by allele-specific mutation testing. In the future, PIK3CA mutations may be potential targets in therapeutic development of esophageal cancer.

\section{Additional file}

Additional file 1: All raw data on somatic mutational analysis by TSACP. (XLSX $38 \mathrm{~kb}$ )

\section{Abbreviations}

AQUA: Automated quantitative fluorescent immunohistochemistry; ESCC: Esophageal squamous cell carcinoma; FFPE: Formalin-fixed paraffinembedded; HR: Hazard ratio; MPS: Massively parallel sequencing; NGS: Nextgeneration sequencing; OS: Overall survival; qPCR: Quantitative PCR; TSACP: TruSeq Amplicon Cancer Panel; UDG: Uracil DNA glycosylase

\section{Funding}

This study was supported by KAKENHI Grant Number 2450136. The funders had no role in study design, data collection and analysis, decision to publish, or preparation of the manuscript.

\section{Availability of data and materials}

All raw dataset on somatic mutational analysis by TSACP are included in Additional file (The file name is "Additional file 1: Table S1").

\section{Authors' contributions \\ TY, MS, and YK analyzed molecular profile by next-generation sequencing. TY, MS, AH, KK, KM, TS, YT, and YK interpreted the patient data. KK performed the histological examination of the esophageal cancer. KM performed statis- tical analysis. TY, MS, TS, and YK were major contributors in writing the manuscript. All authors read and approved the final manuscript.}

\section{Ethics approval and consent to participate}

This study was approved by institutional review boards in Shizuoka Cancer Center and Toyama University (approval number: Shizuoka Cancer Center, T23-3; Toyama University, 22-96). Written informed consent to participate in the study was obtained from each study participant in Toyama University. However, the need for individual informed consent to participate in the study has been waived by institutional review boards in Shizuoka Cancer Center (approval number: Shizuoka Cancer Center, T23-3), as this study was retrospective exploratory research.

\section{Consent for publication}

Not applicable.

\section{Competing interests}

The authors declare that they have no competing interests.

\section{Publisher's Note}

Springer Nature remains neutral with regard to jurisdictional claims in published maps and institutional affiliations.

\section{Author details}

${ }^{1}$ Division of Gastrointestinal Oncology, Shizuoka Cancer Center, 1007 Shimonagakubo Nagaizumi-cho Sunto-gun, Shizuoka 411-8777, Japan. ²Drug Discovery and Development Division, Shizuoka Cancer Center Research Institute, 1007 Shimonagakubo Nagaizumi-cho Sunto-gun, Shizuoka 411-8777, Japan. ${ }^{3}$ Department of Gastroenterology and Hematology, faculty of Medicine, University of Toyama, Toyama, Japan. ${ }^{4}$ Pathology Division, Shizuoka Cancer Center, 1007 Shimonagakubo Nagaizumi-cho Sunto-gun, Shizuoka 411-8777, Japan. ${ }^{5}$ Clinical Trial Coordination Office, Shizuoka Cancer 
Center, 1007 Shimonagakubo Nagaizumi-cho Sunto-gun, Shizuoka 411-8777, Japan. ${ }^{6}$ Division of Esophageal Surgery, Shizuoka Cancer Center, 1007 Shimonagakubo Nagaizumi-cho Sunto-gun, Shizuoka 411-8777, Japan. ${ }^{7}$ Third Department of Internal Medicine, Wakayama Medical University, 811-1, Kimiidera, Wakayama-city, Wakayama 641-0012, Japan.

Received: 19 June 2018 Accepted: 8 August 2018

Published online: 16 August 2018

\section{References}

1. Lin Y, Totsuka Y, He Y, et al. Epidemiology of esophageal cancer in Japan and China. J Epidemiol. 2013;23:233-42.

2. Fujita $\mathrm{H}$, Kakegawa T, Yamana $\mathrm{H}$, et al. Mortality and morbidity rates, postoperative course, quality of life and prognosis after extended radica lymphadenectomy for esophageal cancer. Ann Surg. 1995;222:654-62.

3. Ando $\mathrm{N}$, Kato $\mathrm{H}$, Igaki $\mathrm{H}$, et al. A randomized trial comparing postoperative adjuvant chemotherapy with cisplatin and 5 -fluorouracil versus preoperative chemotherapy for localized advanced squamous cell carcinoma of the thoracic esophagus (JCOG9907). Ann Surg Oncol. 2012;19:68-74.

4. van Hagen P, Hulshof MC, van Lanschot JJ, et al. Preoperative chemoradiotherapy for esophageal or junctional cancer. N Engl J Med. 2012;366:2074-84

5. Gertler R, Stein HJ, Langer R, et al. Long-term outcome of 2920 patients with cancers of the esophagus and esophagogastric junction: evaluation of the new union Internationale Contre le Cancer/American joint Cancer committee staging system. Ann Surg. 2011;253:689-98.

6. Serizawa M, Yokota T, Hosokawa A, et al. The efficacy of uracil DNA glycosylase pretreatment in amplicon-based massively parallel sequencing with DNA extracted from archived formalin-fixed paraffin-embedded esophageal cancer tissues. Cancer Genet. 2015;208:415-27.

7. Do H, Wong SQ, Li J, Dobrovic A. Reducing sequence artifacts in ampliconbased massively parallel sequencing of formalin-fixed paraffin-embedded DNA by enzymatic depletion of uracil-containing templates. Clin Chem. 2013;59:1376-83.

8. Camp RL, Chung GG, Rimm DL. Automated subcellular localization and quantification of protein expression in tissue microarrays. Nat Med. 2002;8: 1323-7.

9. Kawaguchi T, Koh Y, Ando M, et al. Prospective analysis of oncogenic driver mutations and environmental factors: Japan molecular epidemiology for lung cancer study. J Clin Oncol. 2016;34:2247-57.

10. Gao YB, Chen ZL, Li JG, et al. Genetic landscape of esophageal squamous cell carcinoma. Nat Genet. 2014;46:1097-102.

11. Engelman JA, Luo J, Cantley LC. The evolution of phosphatidylinositol 3kinases as regulators of growth and metabolism. Nat Rev Genet. 2006;7: 606-19.

12. Manning BD, Cantley LC. AKT/PKB signaling: navigating downstream. Cell. 2007;129:1261-74.

13. Cantley LC. The phosphoinositide 3-kinase pathway. Science. 2002;296:1655-7.

14. Sawada G, Niida A, Uchi R, et al. Genomic landscape of esophageal squamous cell carcinoma in a Japanese population. Gastroenterology. 2016; 150:1171-82.

15. Zheng $\mathrm{H}$, Wang $Y$, Tang $\mathrm{C}$, et al. TP53, PIK3CA, FBXW7 and KRAS mutations in esophageal Cancer identified by targeted sequencing. Cancer Genomics Proteomics. 2016;13:231-8.

16. Hou J, Jiang D, Zhang J, et al. Frequency, characterization, and prognostic analysis of PIK3CA gene mutations in Chinese esophageal squamous cell carcinoma. Hum Pathol. 2014;45:352-8.

17. Maeng $\mathrm{CH}$, Lee J, van Hummelen $\mathrm{P}$, et al.. High-throughput genotyping in metastatic esophageal squamous cell carcinoma identifies phosphoinositide-3-kinase and BRAF mutations. PLoS One. 2012: 7. doi: https://doi.org/10.1371/journal.pone.0041655.

18. Mori $\mathrm{R}$, Ishiguro $\mathrm{H}$, Kimura $\mathrm{M}$, et al. PIK3CA mutation status in Japanese esophageal squamous cell carcinoma. J Surg Res. 2008;145:320-6.

19. Shigaki $H, B a b a ~ Y$, Watanabe $M$, et al. PIK3CA mutation is associated with a favorable prognosis among patients with curatively resected esophageal squamous cell carcinoma. Clin Cancer Res. 2013;19:2451-9.

20. Song $Y, L i L$, Ou Y, et al. Identification of genomic alterations in oesophageal squamous cell cancer. Nature. 2014;509:91-5.

21. Wang $L$, Shan $L$, Zhang $S$, et al. PIK3CA gene mutations and overexpression: implications for prognostic biomarker and therapeutic target in Chinese esophageal squamous cell carcinoma. PLoS One. 2014. 9 doi: https://doi. org/10.1371/journal.pone.0103021.

22. Liu SY, Chen W, Chughtai EA, et al. PIK3CA gene mutations in Northwest Chinese esophageal squamous cell carcinoma. World J Gastroenterol. 2017; 23:2585-91.

23. Kim HS, Lee SE, Bae YS, et al. PIK3CA amplification is associated with poor prognosis among patients with curatively resected esophageal squamous cell carcinoma. Oncotarget. 2016;7:30691-701.

24. Phillips WA, Russell SE, Ciavarella ML, et al. Mutation analysis of PIK3CA and PIK3CB in esophageal cancer and Barrett's esophagus. Int J Cancer. 2006; 118:2644-6.

25. Zhao L, Vogt PK. Class I PI3K in oncogenic cellular transformation. Oncogene. 2008;27:5486-96.

26. Wang WF, Xie Y, Zhou ZH, Qin ZH, Wu JC, He JK. PIK3CA hypomethylation plays a key role in activation of the PI3K/AKT pathway in esophageal cancer in Chinese patients. Acta Pharmacol Sin. 2013;34:1560-7.

27. Liao X, Morikawa T, Lochhead P, et al. Prognostic role of PIK3CA mutation in colorectal cancer: cohort study and literature review. Clin Cancer Res. 2012; 18:2257-68.

28. De Roock W, Claes B, Bernasconi D, et al. Effects of KRAS, BRAF, NRAS, and PIK3CA mutations on the efficacy of cetuximab plus chemotherapy in chemotherapy-refractory metastatic colorectal cancer: a retrospective consortium analysis. Lancet Oncol. 2010;11:753-62.

29. He Y, Veer LJVT, Mikolajewska-Hanclich I, et al. PIK3CA mutations predict local recurrences in rectal cancer patients. Clin Cancer Res. 2009;15:6956-62.

30. Ogino S, Nosho K, Kirkner GJ, et al. PIK3CA mutation is associated with poor prognosis among patients with curatively resected colon cancer. J Clin Oncol. 2009;27:1477-84.

31. Kawano O, Sasaki H, Endo K, et al. PIK3CA mutation status in Japanese lung cancer patients. Lung Cancer. 2006;54:209-15.

32. Kalinsky K, Jacks LM, Heguy A, et al. PIK3CA mutation associates with improved outcome in breast cancer. Clin Cancer Res. 2009;15:5049-59.

33. Barbareschi M, Buttitta F, Felicioni L, et al. Different prognostic roles of mutations in the helical and kinase domains of the PIK3CA gene in breast carcinomas. Clin Cancer Res. 2007:13:6064-9.

34. Rahman M, Nakayama K, Rahman MT, et al. Clinicopathologic and biological analysis of PIK3CA mutation in ovarian clear cell carcinoma. Hum Pathol. 2012;43:2197-206.

35. Singh RR, Patel KP, Routbort MJ, et al. Clinical validation of a next generation sequencing screen for mutational hotspots in 46 cancer-related genes. J Mol Diagn. 2013;15:607-22

36. Loman NJ, Misra RV, Dallman TJ, et al. Performance comparison of benchtop high-throughput sequencing platforms. Nat Biotechnol. 2012;30:434-9.

37. Ogino $S$, Kawasaki T, Brahmandam M, et al. Sensitive sequencing method for KRAS mutation detection by pyrosequencing. J Mol Diagn. 2005;7:413-21.

38. Yokota T, Shibata N, Ura T, et al. Cycleave polymerase chain reaction method is practically applicable for V-Ki-ras2 Kirsten rat sarcoma viral oncogene homolog (KRAS) N-raf murine sarcoma viral oncogene homolog B1 (BRAF) genotyping in colorectal cancer. Transl Res. 2010;156:98-105.

39. Toyooka M, Konishi M, Kikuchi-Yanoshita R, Iwama T, Miyaki M. Somatic mutations of the adenomatous polyposis coli gene in gastroduodenal tumors from patients with familial adenomatous polyposis. Cancer Res. 1995;55:3165-70.

40. Hare LM, Phesse TJ, Waring PM, et al. Physiological expression of the PI3Kactivating mutation Pik3ca(H1047R) combines with Apc loss to promote development of invasive intestinal adenocarcinomas in mice. Biochem J. 2014:458:251-8

41. Deming DA, Leystra AA, Nettekoven L, et al. PIK3CA and APC mutations are synergistic in the development of intestinal cancers. Oncogene. 2014;33: 2245-54.

42. Zhang J, Jiang D, Li X, et al. Establishment and characterization of esophageal squamous cell carcinoma patient-derived xenograft mouse models for preclinical drug discovery. Lab Investig. 2014;94:917-26.

43. Zhang W, Zhu H, Liu X, et al. Epidermal growth factor receptor is a prognosis predictor in patients with esophageal squamous cell carcinoma. Ann Thorac Surg. 2014;98(2):513-9. 